\title{
Automated type specific ELISA probe detection of amplified NS3 gene products of dengue viruses
}

\author{
V T K Chow, R Y Y Yong, B L Ngoh, Y C Chan
}

\begin{abstract}
Aim-To apply an automated system of nucleic acid hybridisation coupled with the enzyme linked immunosorbent assay (ELISA) for the type specific detection of amplification products of dengue viruses. Methods-Non-structural 3 (NS3) gene targets of reference strains of all four dengue and other flaviviruses, as well as dengue patient viraemic sera, were subjected to reverse transcription and polymerase chain reaction using consensus and dengue type specific primers and digoxigenin-11-dUTP label incorporation. The amplification products were detected by biotinylated type specific primers which served as ELISA capture probes bound to streptavidin coated tubes.
\end{abstract}

Results-Significantly high spectrophotometric absorbance readings were obtained by hybridisation of the consensus and seminested amplification products of all four dengue viruses with their respective capture probes. In contrast, extremely low absorbances were observed for consensus products of Japanese encephalitis, yellow fever, and Kunjin viruses, which served as negative controls. These ELISA data correlated well with agarose gel electrophoresis of dengue type specific amplified products of diagnostic sizes.

Conclusions-The combination of in vitro amplification and antibody based detection offers rapid, type specific, high throughput, and gel-free detection of amplified products of dengue viruses. (F Clin Pathol 1997;50:346-349)

Keywords: dengue viruses; NS3 genes; type specificity; DNA probe hybridisation; enzyme linked immunosorbent assay

Department of Microbiology, Faculty of Medicine, National University of

Singapore

V T K Chow

R Y Y Yong

B L Ngoh

Y C Chan

Correspondence to: Dr Vincent T K Chow, Department of Microbiology, Faculty of Medicine, National University of Singapore, Kent Ridge, Singapore 119260, Republic of Singapore.

Accepted for publication 22 January 1997 for timely supportive treatment. Virus isolation is cumbersome and time consuming, while IgM capture enzyme linked immunosorbent areas such as the Americas as a result of global climatic changes. ${ }^{12}$ In the absence of an effective vaccine or antiviral agent, the laboratory
Dengue viruses are members of the flavivirus dengue, dengue haemorrhagic fever, and denby the mosquito vector, Aedes aegypti, these viruses can precipitate explosive dengue outbreaks predominantly in tropical and subtropi-
cal regions, and even in other geographical and comprise fouritive stranded RNA genom assay (ELISA) and other serological tests do not provide a type specific diagnosis. ${ }^{3}$

To achieve speed, sensitivity, and type specificity, we developed and reported a dengue diagnostic technique based on reverse transcription and polymerase chain reaction (RT-PCR) amplification of the non-structural 3 (NS3) genes of dengue viruses. ${ }^{4-6} \mathrm{We}$ describe here the type specific and nonradioactive detection of RT-PCR products of dengue viruses using an automated system combining nucleic acid hybridisation with ELISA.

\section{Methods}

Reference strains of dengue virus types $1,2,3$, and 4 were purified by precipitation in polyethylene glycol and $\mathrm{NaCl}$ with centrifugation through a sucrose cushion, and viral RNAs were isolated by phenol/chloroform extraction and ethanol precipitation.

RNAs of purified dengue viruses (1 ng each), cytoplasmic RNAs of Japanese encephalitis, yellow fever, Kunjin virus infected C6/36 Aedes albopictus cells ${ }^{8}$ as negative controls $(1-2 \mu \mathrm{g}$ each), and retrospective patient sera from which dengue virus types 2 and 3 had been isolated by cell culture, were subjected to RT-PCR using DV1 and DV3 consensus primers as previously described. ${ }^{4}$ The RT-PCR products served as templates for further PCR to produce digoxigenin incorporated DNA fragments in $50 \mu \mathrm{l}$ volumes containing $1 \times \mathrm{PCR}$ buffer with $2 \mu \mathrm{M} \mathrm{MgCl}$ (Boehringer Mannheim), $200 \mu \mathrm{M}$ each of dATP, dCTP, dGTP, $133 \mu \mathrm{M}$ dTTP, $67 \mu \mathrm{M}$ digoxigenin-11-dUTP (Boehringer Mannheim), with $0.15 \mu \mathrm{M}$ each of DV1 and DV3 primers (for amplifying consensus fragments ${ }^{4}$ ) or of DV1 and DSP1 to DSP4 primers (for generating type specific fragments ${ }^{6}$ ) (table 1). The mixture was heated at $95^{\circ} \mathrm{C}$ for one minute, and $1.25 \mathrm{U}$ of Taq DNA polymerase added at $80^{\circ} \mathrm{C}$, followed by 30 cycles each of $95^{\circ} \mathrm{C}$ for 30 seconds, $50^{\circ} \mathrm{C}$ for one minute, and $72^{\circ} \mathrm{C}$ for one minute; $5 \mu$ of each PCR product was then electrophoresed in agarose gels which were stained with ethidium bromide.

The authenticity of the digoxigenin labelled consensus PCR products was confirmed by subjecting them to seminested PCR using DV1 and DSP1 to DSP4 primers, followed by agarose gel electrophoresis of amplified products with sizes diagnostic for the specific dengue virus types ${ }^{6}$ (table 1). Stringent precautions were adopted to avoid and monitor contamination by "carryover" DNA such as pre- and post-PCR separation of laboratory work, rea- 
Table 1 Nucleotide sequences of RT-PCR primers and biotinylated capture probes specific for NS3 genes of dengue viruses ${ }^{40}$

\begin{tabular}{lll}
\hline Code (and orientation) & & $\begin{array}{c}\text { Target fragment (in bp when } \\
\text { used with DV1) }\end{array}$ \\
\hline DV1 (+) primer & $5^{\prime} \rightarrow 3^{\prime}$ sequence & - \\
DV3 (-) primer & GGRACKTCAGGWTCTCC & 470 \\
DSP1 (-) primer/DSP1B probe & AARTGIGCYTCRTCCAT & 169 \\
DSP2 (-) primer/DSP2B probe & AGTTTCTTTCCTAAACACCTCG & 362 \\
DSP3 (-) primer/DSP3B probe & CCGGTGTGCTCRGCYCTGAT & 265 \\
DSP4 (-) primer/DSP4B probe & TTAGAGTYCTTAAGCGTCTCTTG & 426 \\
\hline
\end{tabular}

(+), sense orientation; (-), antisense orientation; R, A/G; K, G/T; W, A/T; I, inosine; Y, C/T.

The corresponding dengue-type specific (DSP) primers and probes share identical sequences, but the latter are biotinylated at the $5^{\prime}$ or $3^{\prime}$ ends.

gents, amplicons, and equipment, and mandatory inclusion of negative controls. ${ }^{9}$

Using the Enzymun-Test DNA detection kit together with the ES 300 Autoloader automated instrument (Boehringer Mannheim), the DNA fragments which had incorporated digoxigenin were detected by binding to streptavidin coated plastic tubes using four separate biotinylated dengue type specific DSP1 to DSP4 primers which acted as the respective capture probes, DSP1B to DSP4B (table 1). Biotinylation of these probes was achieved either at the 5 ' end during oligodeoxynucleotide synthesis, or at the $3^{\prime}$ end by enzymatic tailing with biotin-16-ddUTP catalysed by terminal transferase.

Each digoxigenin labelled template was denatured in $50 \mathrm{mM} \mathrm{NaOH}$ in the ratio 1:9 (vol/vol) at room temperature for one hour, before loading together with hybridisation solution (a mixture of biotinylated capture probe at 10 or $20 \mu \mathrm{g} / \mathrm{ml}$ and phosphate $\mathrm{pH} 6.5$ buffer in the ratio $1: 100$ ) into streptavidin tubes and allowed to hybridise at $37^{\circ} \mathrm{C}$ for 15 or 30 minutes, and washed.

Immunoreaction was through the addition of conjugate solution (a mixture of peroxidase conjugated polyclonal antidigoxigenin antibody at $1 \mathrm{U} / \mathrm{ml}$ and Tris- $\mathrm{HCl} \mathrm{pH} 7.5$ buffer in the ratio $1: 100$ ), and a second washing step was performed. Colour development was mediated by the addition of substrate-chromogen solution containing di-ammonium 2,2'-azinobis(3-ethylbenzothiazoline-6-sulphonate), and quantitative optical density measurements obtained by spectrophotometry at $422 \mathrm{~nm}$. Each batch included "no DNA" negative controls and performance check positive controls, with most samples in duplicate, and several experiments were repeated at least once.

\section{Results}

Agarose gel electrophoresis of the digoxigenin labelled amplified products showed the expected consensus PCR bands of -470 bp for dengue and related flaviviruses, with semi-nested PCR bands of 169, 362, 265, and 426 bp size specific for dengue virus types 1,2 , 3 , and 4 , respectively (fig 1 ).

Table 2 shows the spectrophotometric readings for an optimal hybridisation at $37^{\circ} \mathrm{C}$ for 30 minutes, wherein the capture probes DSP1B to DSP4B correctly identified the consensus PCR products of the corresponding reference strains of dengue virus types 1 to 4 , but revealed comparatively insignificant absorbances for related flaviviruses, that is, Japanese encephalitis,
A

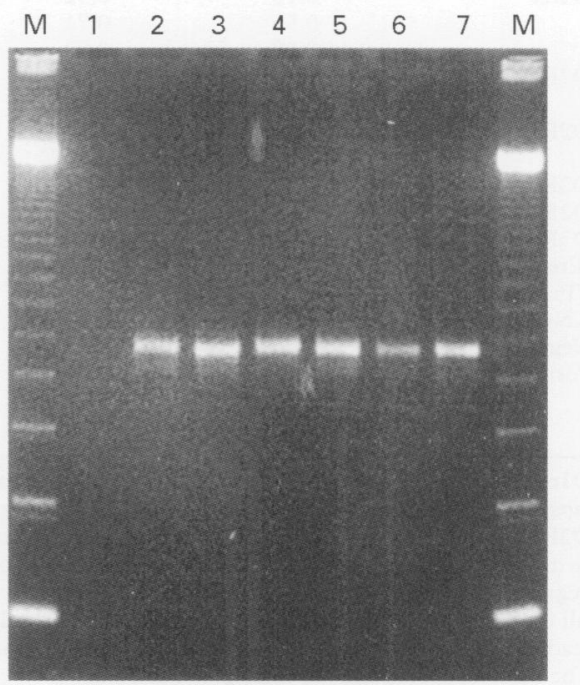

$B$

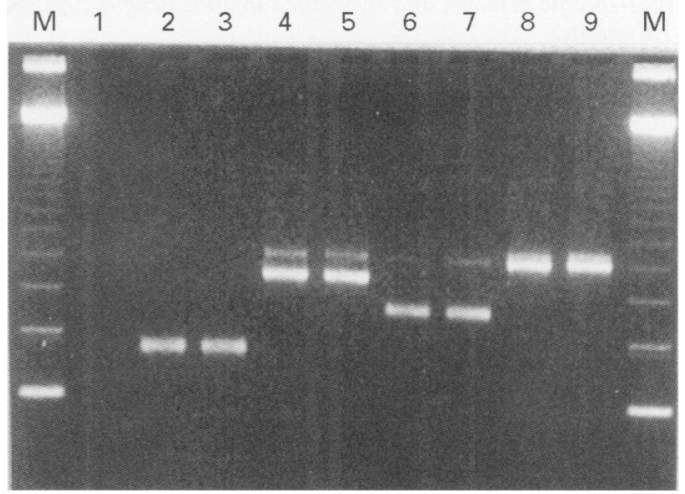

Figure 1 Representative agarose gel electrophoresis of digoxigenin labelled amplification products. The incorporation of digoxigenin in the amplified products accounts for their slower migration relative to the $123 \mathrm{bp}$ $D N A$ ladder molecular mass markers (lanes $M$ ). (A) PCR with consensus primers $D V 1$ and $D V 3$ generated $\sim 470 \mathrm{bp}$ target fragments for dengue virus types 1, 2, 3, 4, fapanese encephalitis, and yellow fever viruses (lanes 2-7, respectively) but not for the "no DNA" negative control (ane 1). (B) Performed in duplicate, PCR using DV1 primer with each type specific primer DSP1 to DSP4 yielded diagnostic target fragments of $169 \mathrm{bp}$ for dengue virus type 1 (lanes 2 and 3), 362 bp for type 2 (lanes 4 and 5), 265 bp for type 3 (lanes 6 and 7), and 426 bp for type 4 (lanes 8 and 9). No product was observed for the "no DNA" negative control (lane 1).

yellow fever, and Kunjin viruses. There was some recognition of certain dengue consensus products by a non-homologous probe, for example, consensus amplicons of dengue virus type 1 by DSP2B capture probe. Notwithstanding this, the relatively minimal degree of cross reactivity is unlikely to pose problems of data interpretation since the dengue virus type in each sample can be readily identified by the 
Table 2 ELISA absorbance values of DNAs amplified with dengue consensus primers, and hybridised against dengue type specific capture probes at $37^{\circ} \mathrm{C}$ for 30 minutes

\begin{tabular}{|c|c|c|c|c|}
\hline \multirow[b]{2}{*}{ Sample } & \multicolumn{4}{|c|}{ Absorbance readings for capture probes } \\
\hline & $D S P 1 B$ & $D S P 2 B$ & $D S P 3 B$ & DSP4B \\
\hline \multirow[t]{3}{*}{ D1 ref } & 7.20 & 1.52 & 0.10 & 0.13 \\
\hline & 5.69 & 1.28 & 0.73 & 0.26 \\
\hline & 4.51 & 1.30 & 0.12 & 0.12 \\
\hline \multirow[t]{3}{*}{ D2ref } & 0.16 & 5.12 & 0.04 & 0.10 \\
\hline & 0.50 & 5.91 & 0.32 & 0.30 \\
\hline & 0.08 & 4.02 & 0.04 & 0.04 \\
\hline \multirow[t]{3}{*}{ D3ref } & 0.07 & 0.03 & 4.19 & 0.09 \\
\hline & 0.58 & 0.44 & 5.84 & 0.39 \\
\hline & 0.06 & 0.06 & 3.76 & 0.07 \\
\hline \multirow[t]{3}{*}{ D4ref } & 0.10 & 0.32 & 0.59 & 4.91 \\
\hline & 0.56 & 0.71 & 1.03 & 5.56 \\
\hline & 0.08 & 0.20 & 0.34 & 3.05 \\
\hline \multirow[t]{2}{*}{ D2RS2 } & 0.49 & 2.08 & 0.03 & 0.03 \\
\hline & 0.07 & 4.95 & 0.09 & 0.05 \\
\hline \multirow[t]{2}{*}{ D2RS5 } & 0.06 & 5.03 & 0.06 & 0.04 \\
\hline & 0.09 & 5.17 & 0.08 & 0.05 \\
\hline D2RS8 & 0.08 & 3.94 & 0.06 & 0.05 \\
\hline D2RS13 & 0.12 & 4.82 & 0.12 & 0.15 \\
\hline D3RS10 & 0.13 & 0.19 & 5.26 & 0.15 \\
\hline JEref & 0.08 & 0.38 & 0.04 & 0.04 \\
\hline YFref & 0.65 & 0.07 & 0.06 & 0.05 \\
\hline KNref & 0.09 & 0.05 & 0.05 & 0.04 \\
\hline Negative & 0.06 & 0.03 & 0.03 & 0.03 \\
\hline \multirow[t]{3}{*}{ Positive } & 4.31 & 4.48 & 4.38 & 4.20 \\
\hline & 2.99 & 3.11 & 3.15 & 2.92 \\
\hline & 3.64 & 3.40 & 3.41 & 3.40 \\
\hline
\end{tabular}

D1 ref, D2ref, D3ref, D4ref, JEref, YFref, KNref: reference strains of dengue virus types 1, 2, 3, 4, Japanese encephalitis, yellow fever, and Kunjin viruses, respectively.

D2RS2, D2RS5, D2RS8, D2RS13: retrospective patient serum samples positive for dengue 2 virus; D3RS10, retrospective patient serum positive for dengue 3 virus; Negative, "no DNA" negative controls; Positive, performance check positive controls.

All the absorbance readings represent the means of duplicate samples except for the first batch of readings for D1 ref, D2ref, D3ref, D4ref, and positive samples.

The significant readings are highlighted in bold.

Table 3 Absorbance values of DNAs amplified with DV1 primer and DSP1 to DSP4 type-specific primers, and hybridised against dengue type specific capture probes at $37^{\circ} \mathrm{C}$ for 15 minutes

\begin{tabular}{lllll}
\hline \multicolumn{5}{c}{ Absorbance readings for capture probes } \\
\cline { 2 - 5 } Sample & DSP1B & $D S P 2 B$ & $D S P 3 B$ & $D S P 4 B$ \\
\hline D1ref & 4.60 & 0.05 & 0.02 & 0.02 \\
& $\mathbf{4 . 2 8}$ & 0.04 & 0.02 & 0.03 \\
D2ref & 0.80 & 5.09 & 0.04 & 0.03 \\
& 0.03 & $\mathbf{5 . 0 8}$ & 0.04 & 0.04 \\
D3ref & 0.06 & 0.03 & 4.20 & 0.03 \\
& 0.02 & 0.02 & 4.91 & 0.04 \\
D4ref & 0.06 & 0.07 & 0.22 & 2.48 \\
& 0.02 & 0.03 & 0.05 & 3.44 \\
D2RS2 & 0.04 & 5.15 & 0.07 & 0.07 \\
D2RS4 & 0.04 & 4.77 & 0.04 & 0.03 \\
D2RS5 & 0.05 & 5.26 & 0.04 & 0.04 \\
D2RS9 & 0.07 & 4.57 & 0.04 & 0.05 \\
D2RS13 & 0.05 & 5.20 & 0.05 & 0.07 \\
D3RS10 & 0.05 & 0.02 & 4.90 & 0.02 \\
D3RS11 & 0.05 & 0.38 & 4.66 & 0.04 \\
Negative & 0.01 & 0.01 & 0.01 & 0.00 \\
& 0.01 & 0.00 & 0.00 & 0.01 \\
Positive & 3.16 & 2.94 & 2.93 & 3.12 \\
& 2.96 & 2.99 & 3.06 & 3.06 \\
& 2.92 & 3.05 & 3.09 & 2.91
\end{tabular}

D1ref, D2ref, D3ref, D4ref: reference strains of dengue virus types 1,2,3, and 4, respectively D2RS2, D2RS4, D2RS5, D2RS9, D2RS13: retrospective patient sera positive for dengue 2 virus; D3RS10, D3RS11, retrospective patient sera positive for dengue 3 virus; Negative, "no DNA" negative controls; Positive, performance check positive controls.

All the readings were the means of duplicate samples except for retrospective sera.

The significant readings are highlighted in bold.

highest reading out of four comparative results derived from the four probes. Further, there should be no real problem with data analysis if the homologous controls are always carried through in each batch of tests. No significant differences in readings were observed for capture probes biotinylated by 3 ' end tailing or by 5 ' chemical coupling. The amplified consensus fragments of retrospective serum specimens from four patients with dengue type 2 and one patient with dengue type 3 were appropriately detected by DSP2B and DSP3B probes, respectively.

With a hybridisation at $37^{\circ} \mathrm{C}$ for 15 minutes, unequivocally high absorbance readings were obtained for capture probes DSP1B to DSP4B hybridised with their relevant reference dengue virus type specific seminested PCR products. In addition, the type specific amplified products of retrospective sera from five and two patients with dengue types 2 and 3, respectively were each recognised by the corresponding capture probe (table 3 ). The negative and positive controls were valid in each batch of experiments (tables 2 and 3 ).

\section{Discussion}

Not unexpectedly, the absorbance readings obtained with products of amplification of dengue viraemic sera and reference virus strains by the more sensitive seminested PCR technique $^{6}$ were more specific than those derived from consensus amplicons. ${ }^{4}$ There is no danger of the biotinylated DSP1B to DSP4B probes detecting the corresponding non-biotinylated seminested PCR primers as ELISA signals since both probes and primers are of the same nucleic acid orientation, as supported by the specific data generated with positive samples compared with negative controls.

Overall, the highly reproducible results attest to the reliability of the ELISA probe hybridisation system. The type specificity of ELISA detection compared very favourably with visualisation of ethidium bromide stained agarose gel electrophoresis. One important advantage of such an ELISA based strategy for PCR product detection is obviating the requirement for agarose gel electrophoresis and the use of radioactive gene probes, thus reducing the number of post-PCR manipulations.

The convenient automation of the ELISA format renders it feasible for high throughput screening within hours, while the associated computer software facilitates processing of data, which can be stored in files or as hard copies. Such automation of high capacity should be particularly cost-effective for laboratories engaged in the PCR diagnosis of large numbers of specimens. Furthermore, the accurate and precise spectrophotometric evaluation permits the rapid identification of the viral pathogen in viraemic sera. In our previous prospective study comparing PCR with virus isolation and dengue serology, we have suggested that serum specimens for PCR should preferably be collected within two to five days of fever, which generally coincides with the period of viraemia. ${ }^{10}$ Although not assessed in our study, this technology has quantitative potential by allowing the measurement of viral load via RNA quantitation ${ }^{11}$ which may represent a useful dynamic marker of the disease process.

The combination of two biological tools (in vitro nucleic acid amplification and antibody based detection) together with good quality assurance-for example, valid controls and suitable nucleic acid standards ${ }^{9}$ - could have 
further clinical applications. This combined approach has already been exploited for the detection of other microbial pathogens including human immunodeficiency virus, ${ }^{12}$ herpes simplex virus, ${ }^{13}$ hepatitis C virus, ${ }^{14}$ Bordetella pertussis, ${ }^{15}$ and Neisseria meningitidis. ${ }^{16}$

We are grateful to Mrs $M$ Reuschling and $\mathrm{Dr} M$ Theis, Boehringer Mannheim, Germany, for providing the reagents, kits and ES 300 analyser, and to Mr D Lam for technical advice. This study was supported by a research grant (RP930337) from the National University of Singapore.

1 Monath TP. Dengue: the risk to developed and developing countries. Proc Natl Acad Sci USA 1994;91:2395-400.

2 Patz JA, Epstein PR, Burke TA, Balbus JM. Global climate change and emerging infectious diseases. $\mathscr{f} A M A 1995 ; 275$

3 World Health Organization. Laboratory diagnosis. In Dengue haemorrhagic fever: diagnosis, treatment and control. Geneva: World Health Organization, 1986:23-9.

4 Chow VTK, Seah CLK, Chan YC. Use of NS 3 consensus primers for the polymerase chain reaction amplification and sequencing of dengue viruses and other flaviviruses. Arch Virol 1993;133:157-70.

5 Seah CLK, Chow VTK, Tan HC, Chan YC. Rapid, singlestep RT-PCR typing of dengue viruses using five NS3 gene step RT-PCR typing of dengue viruses using

primers. F Virol Methods 1995;51:193-200.
6 Seah CLK, Chow VTK, Chan YC. Semi-nested PCR using Seah CLK, Chow VTK, Chan YC. Semi-nested PCR using
NS3 primers for the detection and typing of dengue viruses in clinical serum specimens. Clin Diagn Virol 1995;4:113 20 .
7 Rico-Hesse R, Pallansch MA, Nottay BK, Kew OM Geographic distribution of wild poliovirus type 1 genotypes. Virology 1987;160:311-22.

8 Gough NM. Rapid and quantitative preparation of cytoplasmic RNA from small numbers of cells. Anal Biochem 1988; 173:93-5.

9 Kitchin PA, Bootman JS. Quality control of the polymerase chain reaction. Rev Med Virol 1993;3:107-14.

10 Seah CLK, Chow VTK, Chan YC, Doraisingham S. A comparative, prospective study of serological, virus isolation and PCR amplification techniques for the laborator diagnosis of dengue infection. Serodiagn Immunother Infect Dis 1995;7:55-8.

11 Malcomson RDG, McCullough CT, Bruce DJ, Harrison DJ. The scope of quantitative polymerase chain reaction assays in clinical molecular pathology. 7 Clin Pathol: Mol Pathol 1995;48:M178-83.

12 Mallet F, Hebrard C, Brand D, Chapuis E, Cros P, Allibert $\mathrm{P}$, et al. Enzyme-linked oligosorbent assay for detection of polymerase chain reaction-amplified human immunodefipolymerase chain reaction-amplified human immun

13 Kessler HH, Pierer K, Weber B, Sakrauski A, Santner B Stuenzner D, et al. Detection of herpes simplex virus DNA from cerebrospinal fluid by PCR and a rapid, nonradioactive hybridization technique. $\mathcal{F}$ Clin Microbiol 1994;32: 1881-6.

14 Besnard NC, Andre PM. Automated quantitative determination of hepatitis $\mathrm{C}$ virus viremia by reverse transcriptionPCR. F Clin Microbiol 1994;32:1887-93.

15 Lichtinghagen $R$, Diedrich-Glaubitz $R$, Von Horsten $B$. Identification of Bordetella pertussis in nasopharyngeal swabs using the polymerase chain reaction: evaluation of detection methods. Eur f Clin Chem Clin Biochem 1994;32: 161-7.

16 Davison E, Borrow R, Guiver M, Kaczmarski EB, Fox AJ. The adaptation of the IS 1106 PCR to a PCR ELISA
format for the diagnosis of meningococcal infection. Serodiagn Immunother Infect Dis 1996;8:51-6. 